\title{
Arp en ses ateliers d'art et d'écriture, sous la direction d'Aimée Bleikasten et Maryse Staiberg, Actes du Colloque de Strasburg
}

\section{Marcella Biserni}

\section{(2) OpenEdition}

\section{Journals}

\section{Edizione digitale}

URL: http://journals.openedition.org/studifrancesi/4182

DOI: 10.4000/studifrancesi.4182

ISSN: 2421-5856

\section{Editore}

Rosenberg \& Sellier

\section{Edizione cartacea}

Data di pubblicazione: 1 juillet 2012

Paginazione: 361

ISSN: 0039-2944

\section{Notizia bibliografica digitale}

Marcella Biserni, «Arp en ses ateliers d'art et d'écriture, sous la direction d'Aimée Bleikasten et Maryse Staiberg, Actes du Colloque de Strasburg», Studi Francesi [Online], 167 (LVI | II) | 2012, online dal 30 novembre 2015, consultato il 07 janvier 2021. URL: http://journals.openedition.org/studifrancesi/4182 ; DOI: https://doi.org/10.4000/studifrancesi.4182

Questo documento è stato generato automaticamente il 7 janvier 2021.

\section{(c) (i) (9)}

Studi Francesi è distribuita con Licenza Creative Commons Attribuzione - Non commerciale - Non opere derivate 4.0 Internazionale. 


\title{
Arp en ses ateliers d'art et d'écriture, sous la direction d'Aimée Bleikasten et Maryse Staiberg, Actes du Colloque de Strasburg
}

\author{
Marcella Biserni
}

\section{NOTIZIA}

Arp en ses ateliers d'art et d'écriture, sous la direction d'Aimée BLEIKASTEN et Maryse STAIBERG, Actes du Colloque de Strasburg, 29, 30 et 31 janvier 2009, Strasbourg, Éditions des Musées de Strasbourg, Peronnas, Sepec, 2011, pp. 301.

1 Il Museo d'arte moderna e contemporanea di Strasburgo ha ospitato nel 2009 la grande esposizione: Art is Arp. Il sottotitolo Dessins, collages, reliefs, sculptures, poésies mette in risalto l'interdisciplinarità dell'artista e sulla scia della predilezione arpiana per l'opera letteraria si inserisce anche il convegno internazionale Arp en ses ateliers d'art et d'écriture, organizzato contestualmente alla mostra. Il volume, che ne raccoglie gli atti, rispetta esattamente l'ordine con cui Arp stesso amava auto-definirsi: prima poeta, poi scultore e infine pittore.

2 Dopo la prima parte «Arp en son pays», che racchiude gli interventi ufficiali di apertura di Alain BERETZ, Joëlle PIJAUDIER-CABOT e Antoine PONCET, nonché la presentazione di Aimée BLEIKASTEN, il poeta Pierre DHAINAUT apre la sezione «Le travail d'écriture» con Arp ou la beauté corps et âme (pp.34-37), citando alcuni versi dei poemi raccolti in Jours effeuillés (1965) e esaltando l'attitudine dell'artista a produrre e non a imitare, in un connubio tra arte, natura e vita, oltre che tra anima e corpo. Il filosofo Daniel PAYOT, in Les Voies du «comme» (pp. 38-42), si interessa alle prose di On My Way, Poetry and Essays (New York, 1948), in cui il termine di comparazione comme conduce, per via metaforica, alla riconciliazione perfetta tra natura e creazione individuale, sul cammino della 
modernità. In Voix, geste, forme, ou «la flamme chantante du Néant» (pp. 43-55) Georges BLOESS sonda i misteri dell'opera di Arp cercando di isolarne l'ispirazione folgorante e scava nelle profondità intime di quel «chant intérieur», che lo porta dal sogno e dal vuoto familiare fino al risveglio dello spirito infantile. Valérie Colucci analizza due testi raccolti in Die Wolkenpumpe (1920) durante il periodo dada. Il suo articolo Esquisses poétiques du jeune Arp: images, couleurs, matières, rythmes (pp. 56-71) cerca di captare la ricchezza dei colori e dei materiali oltre che la magia della musica e del ritmo. Infine, Aimée BLEIKASTEN, in Palimpsestes, écriture et réécritures (pp. 72-95), parte dal poema del 1963 Palimpsestes e tenta di mostrare l'ipertestualità poetica nelle fasi di riscrittura di sue composizioni, riviste sulla base di restrizioni formali da perseguire rigorosamente.

La sezione «Fables d'atelier» riporta l'originale tedesco di Arp e poi la traduzione francese inedita di Werkstattfabeln. In Parole poétique et geste créateur: Jean Arp, "Fables d'atelier" (pp.112-121) Maryse STAIBER mette in luce le rêveries piene di humour e di trouvailles ludiche che Arp poeta invoca nel testo e che si mescolano al lavoro di pittorescultore. Il richiamo esplicito ai presocratici e al ruolo del mandala orientale in quest'opera è preso in esame da Rudolf sUTER in Arp revisite Dada (pp. 137-146). L'intervento di Agathe MAREUGE (Le Nombril, noyau dynamique de la cosmologie arpienne, pp.122-136) focalizza la sua argomentazione sull'ombelico, simbolo e immagine ricorrente nell'opera arpiana sia poetica che figurativa, e fa da pendant alla sezione che segue «Les Ateliers d'art» e all'articolo di Eric ROBERTSON Traduction, concrétion, décomposition (pp.156-167), incentrato sul legame indissolubile tra l'arte e la poesia bilingue di Arp. Michèle MARTEL espone le liaisons tra la creazione arpiana e le teorie di Pestalozzi (Influence(s) du Cercle pestalozzien de Zurich sur l'oeuvre précoce d'Arp, pp.166-177), mentre Liliane MEFFRE in «L'enfance néolithique» et le primitivisme dans la création arpienne (pp. 178-183), da storica dell'arte, ne sottolinea l'aspetto primitivista post-dadaista, partendo dal testo di Carl Einstein pubblicato in «Documents» (1930). Sylvain CHARTIER riporta la sua esperienza di scultore contemporaneo a contatto con le foreste dei Vosges e l'inevitabile parallelismo con la creazione arpiana (Du dessin à la sculpture, de la sculpture au dessin, pp.184-191). Isabelle EWIG, commissario dell'esposizione, attraverso un originale collage testuale svela i retroscena organizzativi dell'allestimento (Retour sur "Art is Arp". De l'atelier à l'exposition, pp. 192-217).

In «Le travail en commun» Henri BÉHAR, con Une amitié stellaire: Arp et Tzara en leur atelier (pp. 218-232), evidenzia il particolare «dialogue par le livre» instauratosi tra i due grazie alle illustrazioni che il pittore ha realizzato delle poesie dell'amico dadaista. Bärbel REETZ, in «Dada n'était pas une farce» - Hans Arp, Hugo Ball et Emmy Ennings inventent un contre-monde (pp. 233-247), mette a disposizione la sua conoscenza della biografia della coppia tedesca per illustrare la loro lunga collaborazione con Arp e Sophie Taeuber al tempo dell'esperienza dadaista a Zurigo. Les Décors de l'Aubette à Strasbourg: genèse d'une ceuvre en commun (pp. 248-268) di Denis STEINMETZ riporta in auge la figura di S. Taeuber nell'équipe formata con Arp e Theo van Doesburg per la decorazione degli spazi dell'edificio e rende giustizia al «langage plastique et poétique» impiegato da Arp in quest'occasione. Infine, François PÉTRY ripercorre le tracce di Arp adolescente e delle opere realizzate per dei privati durante il periodo trascorso con la compagna a Strasburgo (Ateliers et chantiers strasbourgeois de Hans Arp et Sophie Taeuber-Arp, pp. 269-288). 